\title{
Effect of bariatric surgery on asthma control, lung function and bronchial and systemic inflammation in morbidly obese subjects with asthma
}

\author{
Astrid van Huisstede, ${ }^{1}$ Arjan Rudolphus, ${ }^{1}$ Manuel Castro Cabezas, ${ }^{2}$ Laser Ulas Biter, ${ }^{3}$ \\ Gert-Jan van de Geijn, ${ }^{4}$ Christian Taube, ${ }^{5}$ Pieter S Hiemstra, ${ }^{5}$ Gert-Jan Braunstahl ${ }^{1}$
}

- Additional material is published online only. To view please visit the journal online (http://dx.doi.org/10.1136/ thoraxjn-2014-206712)

'Department of Pulmonology, Sint Franciscus Gasthuis, Rotterdam, The Netherlands 2Department of Internal Medicine, Sint Franciscus Gasthuis, Rotterdam,

The Netherlands

${ }^{3}$ Department of Surgery,

Sint Franciscus Gasthuis, Rotterdam, The Netherlands ${ }^{4}$ Department of Clinical Chemistry, Sint Franciscus Gasthuis, Rotterdam,

The Netherlands ${ }^{5}$ Department of Pulmonology, Leiden University Medical Center, Leiden,

The Netherlands

Correspondence to Astrid van Huisstede, Department of Pulmonology, Sint Franciscus Gasthuis, Kleiweg 500, Rotterdam 3045 PM, The Netherlands; a.vanhuisstede@sfg.n

Received 18 December 2014 Revised 9 March 2015 Accepted 17 March 2015 Published Online First 1 May 2015

\section{ABSTRACT}

Background The pathogenesis of asthma in obese subjects is poorly understood and has been described as a specific phenotype in these patients. Weight loss improves asthma control and lung function. Whether this improvement is the result of better mechanical properties of the airways or decreased systemic and bronchial inflammation remains unclear.

Methods A longitudinal study in obese patients with asthma (bariatric surgery and asthma group (BS+A), $n=27$ ) and obese control (bariatric surgery without asthma group ( $\mathrm{BS}-\mathrm{A}), \mathrm{n}=39$ ) subjects undergoing bariatric surgery, and obese patients with asthma without intervention (no bariatric surgery and asthma group (NBS+A), $n=12$ ). Lung function, asthma control, cellular infiltrates in bronchial biopsies and circulating markers of systemic inflammation were measured during follow up at 3, 6 and 12 months.

Results Bariatric surgery resulted in a profound weight loss at 12 months. In the BS+A group as well as the BS -A group $\mathrm{FEV}_{1}$, functional residual capacity, total lung capacity improved, whereas $\mathrm{FEV}_{1} / \mathrm{FVC}$ only improved in the BS-A group. In addition, Asthma Control Questionnaire (ACQ), Asthma Quality of Life Questionnaire, inhaled corticosteroid use and $\mathrm{PD}_{20}$ improved in $B S+A$, whereas in the NBS+A group only ACQ improved. Small airway function $R_{5}-R_{20}$ improved in both surgery groups, however the change in the $B S$ $+A$ group was greater, resulting in a comparable $R_{5}-R_{20}$ between $B S+A$ and $B S-A$ at 12-month follow-up. Besides improvement of systemic inflammation (high sensitivity C-reactive protein, adiponectin and leptin) after $B S$, only a decrease in mast cell numbers was detectable in the $\mathrm{BS}+\mathrm{A}$ group.

Conclusions Bariatric surgery improved small airway function, decreased systemic inflammation and number of mast cells in the airways. These effects could explain the improvement of asthma control, quality of life and lung function. Therefore bariatric surgery, in addition to all other positive effects, also improves asthma in subjects with morbid obesity.

Trial registration number 3204

\section{INTRODUCTION}

Asthma prevalence has increased over recent decades, ${ }^{1}{ }^{2}$ concurrently with the prevalence of obesity, suggesting a possible link between obesity and asthma. ${ }^{3}$ In a prospective study on the relationship between obesity and asthma, obese patients

\section{Key messages}

What is the key question?

- Is the improvement of asthma control and lung function in obese subjects with asthma after bariatric surgery due to altered better mechanical properties of the airways or decreased systemic and bronchial inflammation?

\section{What is the bottom line?}

- Bariatric surgery improved not only small airway function, which could explain the improvement of asthma control, quality of life and lung function, but also induced a decrease in systemic inflammation and bronchial inflammation in morbidly obese subjects with asthma.

\section{Why read on?}

- This is the first study analysing bronchial biopsies in obese patients with asthma before and after bariatric surgery.

appeared to have a 2.6 times elevated risk of developing asthma. ${ }^{4}$ In addition, obesity is associated with increased severity of asthma. Obese patients with asthma have worse asthma control ${ }^{5}$ and respond less to standard therapy compared with lean patients with asthma. ${ }^{6}$

A recent position paper on weight loss interventions in asthma ${ }^{7}$ concluded that the evidence for benefits from weight reduction on asthma outcomes is weak. Unfortunately, only studies with dietary weight loss were included, and a sustained effect of weight loss through lifestyle changes is small. In contrast, bariatric surgery leads to a more pronounced and persistent weight loss in subjects who are morbidly obese. ${ }^{8}$ Therefore, weight loss by bariatric surgery may have more profound effects on asthma.

Asthma in patients who are obese has been described as a specific phenotype, with high symptom expression and late onset of symptoms. Whether bronchial inflammation in obese subjects with asthma is characterised by eosinophilic or neutrophilic inflammation, or both, is a matter of debate in the literature. Different methods were 
used to (indirectly) measure bronchial inflammation. So far, only two studies have reported on the analysis of bronchial biopsies in obese subjects with asthma, ${ }^{10}{ }^{11}$ in which, especially in those who are morbidly obese, little inflammation was detectable in the airways. Although previous studies have shown that bariatric surgery does improve asthma control, lung function and systemic inflammation, ${ }^{12-18}$ the effect on bronchial inflammation is unknown. Previous studies were conducted in small groups and either lacked follow up of a control group, ${ }^{12} 1315$ or they lacked a non-intervention control group. ${ }^{13}$ 14 $16-18$ To our knowledge, this is the first study analysing bronchial biopsies before and after bariatric surgery. We hypothesised that bariatric surgery and weight loss would result in improved bronchial obstruction, and reduced systemic and bronchial inflammation. To test this, we performed a cohort study to evaluate the impact of weight loss by bariatric surgery on asthma control, lung function and bronchial and systemic inflammation after 12-month follow-up. Baseline data (including subjects without 12-month follow-up) were published previously. ${ }^{11}$

\section{METHODS}

\section{Study population}

This study is part of a larger study, of which results have been reported before. ${ }^{11} 19$ Inclusion and exclusion criteria of this study are described in the online supplementary material. In summary, subjects were between 18 and 50 years old, had a body mass index (BMI) above $35 \mathrm{~kg} / \mathrm{m}^{2}$, and were excluded if they smoked more than 10 cigarettes per day or had smoked more than 10 pack years.

The local ethics committee (Toetsingscommissie Wetenschappenlijk Onderzoek Rotterdam e.o.) approved the study protocol (Netherlands Trial Register 3204), and all subjects gave written informed consent.

The subjects in this study were divided into three groups: a group of morbidly obese subjects with asthma scheduled for bariatric surgery $(\mathrm{BS}+\mathrm{A})$, a group of morbidly obese subjects without asthma also scheduled for bariatric surgery (BS-A), and a group of obese subjects with asthma not undergoing bariatric surgery $(\mathrm{NBS}+\mathrm{A})$. The first two groups were patients who applied for bariatric surgery in the Sint Franciscus Gasthuis; the third group was a control group included from our outpatient clinic.

The primary endpoint of the study was the change of $\mathrm{FEV}_{1} /$ FVC at 12-month follow-up. Secondary endpoints were other lung function parameters, asthma symptoms (asthma control, asthma-related quality of life, medication use), change of comorbidities (obstructive sleep apnoea syndrome (OSAS), gastro-oesophageal reflux disease) airway inflammation and systemic inflammation at 3,6 and 12-month follow-up. Only subjects with a follow-up at 12 months were analysed. Baseline data (including subjects without 12-month follow-up) were published previously. ${ }^{11}$

\section{Definition of asthma}

Asthma was defined according to Global Initiative for Asthma (GINA) guidelines ${ }^{1}$ as both the presence of symptoms and either an increase of $\geq 12 \%$ and $200 \mathrm{~mL}$ in $\mathrm{FEV}_{1}$ after salbutamol, or a positive provocation test (methacholine $\mathrm{PD}_{20}<1.8 \mathrm{mg}$ ). Patients without airway reversibility and a negative provocation test formed the control group.

Descriptions of pulmonary function tests (spirometry, ${ }^{20} 21$ exhaled nitric oxide, ${ }^{22}$ impulse oscillometry, diffusion capacity ${ }^{23}$ and methacholine provocation testing ${ }^{24}$ ) can be found in the online supplementary material, along with descriptions of the questionnaires used (Asthma Quality of Life Questionnaire $(\mathrm{AQLQ})^{26}$ and Asthma Control Questionnaire $(\mathrm{ACQ})^{27}$ ), comorbidities (obstructive sleep apnoea syndrome (OSAS), ${ }^{28}$ gastro-oesophageal reflux disease ${ }^{29}$ and metabolic syndrome ${ }^{30}$ ), atopy definitions, laboratory measurements and the formula used for the percentage excess weight loss (\%EWL).

\section{Bronchial biopsies and immunohistochemistry}

Peripheral bronchial biopsies were taken prior to laparoscopic bariatric surgery (either sleeve gastrectomy or Roux-and-Y gastric bypass), after routine anaesthesia with desflurane and remifentanil, directly after intubation. ${ }^{11}$ Twelve months after bariatric surgery bronchial biopsies were taken during cosmetic surgery or during an outpatient visit. Bronchoscopy was performed according to the British Thoracic Society guidelines ${ }^{31}$ using a flexible fibre optic bronchoscope (Olympus). Four biopsies were taken from the segmental carina from the right middle and lower lobe using a forceps (Boston Scientific, Radial Jaw 3). The $4 \mu \mathrm{m}$ sections from paraffin-embedded bronchial biopsies were stained for EG2 (eosinophils), neutrophil elastase (neutrophils), AA1 (mast cells), CD68 (macrophages), CD20 (B cells), CD8, CD4 and CD3 (T cells), or negative control, and enumerated as cells per square millimetre submucosa on digitalised images. The smallest $10 \%$ of selected surfaces of biopsies were not used for analysis. The mean cell count of an individual was the mean of two to four biopsies. The observer was blinded with regard to the patient's number and clinical status during selection, processing and analysis of the biopsy samples. Baseline data were published previously. ${ }^{11}$

\section{Power calculation and statistical analysis}

The group size was powered on the expected change in $\mathrm{FEV}_{1} /$ FVC ratio after bariatric surgery. Based on a pilot study and published data we assumed that in the $\mathrm{BS}+\mathrm{A}$ group the $\mathrm{FEV}_{1} /$ FVC ratio would increase from $72 \%$ to $75 \%(\mathrm{SD} \pm 6)$. The increase of $3 \%$ represents an effect size of 0.5 . To find a difference in the group with obesity and asthma before and after operation with an $\alpha$ error of $5 \%$ and a power of $80 \%$, we needed at least 27 participants per group. With an expected dropout of $25 \%$ over 1 -year follow-up we aimed at 40 patients per subgroup.

For the comparison between the three groups at baseline, the independent samples median test for scaled data or the $\chi^{2}$ or Fisher exact test were used. For all groups, baseline data were compared with 12-month follow-up data, using a nonparametric test (related-samples Wilcoxon signed rank test). Unless indicated otherwise, all data are expressed as median (min-max) for paired data for scale variables or percentage for categorical variables. Spearman correlation coefficient (R) was calculated. All analyses were performed using SPSS V.21.0 software (SPSS Inc., Chicago, Illinois, USA). Given the exploratory nature of this study, we did not control for multiple comparisons. Results were evaluated at 95\% CI at a two-sided significance threshold of $\mathrm{p}<0.05$.

\section{RESULTS}

A total of 101 patients were included in the initial study. ${ }^{11}$ At 12-month follow-up data were available for 78 subjects, which were included in the present analysis. In table 1 (and online supplementary table S1B) the baseline subject characteristics are shown (27 BS+A, $39 \mathrm{BS}-\mathrm{A}$ and $12 \mathrm{NBS}+\mathrm{A})$. There were no significant differences in demographic characteristics between the groups, with the exception of BMI. 
Table 1 Demographics of the study population

\begin{tabular}{|c|c|c|c|c|}
\hline & $\mathrm{NBS}+\mathrm{A}$ & $\mathrm{BS}+\mathrm{A}$ & BS-A & $p$ Value \\
\hline \multicolumn{5}{|l|}{ Number } \\
\hline Baseline & 12 & 27 & 39 & \\
\hline 3-month follow-up & 11 & 26 & 33 & \\
\hline 6-month follow-up & 11 & 21 & 34 & \\
\hline 12-month follow-up & 12 & 27 & 39 & \\
\hline Gender (\% female) & $91.7 \%$ & 74.1 & 82.1 & 0.494 \\
\hline Ethnicity (\% non-Caucasian) & $25.0 \%$ & $14.8 \%$ & $15.4 \%$ & 0.714 \\
\hline Age (years) & $33(20-45)$ & $36(19-48)$ & $39(18-50)$ & 0.440 \\
\hline Weight $(\mathrm{kg})$ & $103(82-132)$ & $130(101-202)$ & $126(94-199)$ & 0.044 \\
\hline Body mass index $\left(\mathrm{kg} / \mathrm{m}^{2}\right)$ & $35.6(30.9-53.9)$ & $45.1(38.4-63.8)$ & $43.1(35.6-58.6)$ & 0.015 \\
\hline Abdominal circumference $(\mathrm{cm})$ & $119(102-155)$ & $133(112-165)$ & $127(103-200)$ & 0.016 \\
\hline Smoking status & & & & 0.178 \\
\hline$\%$ never smoked & $75.0 \%$ & $55.6 \%$ & $71.8 \%$ & \\
\hline$\%$ stopped smoking & $16.7 \%$ & $11.1 \%$ & $17.9 \%$ & \\
\hline$\%$ current smoker & $8.3 \%$ & $33.3 \%$ & $10.3 \%$ & \\
\hline Pack years & $0(0-0)$ & $0(0-10)$ & $0(0-10)$ & 0.311 \\
\hline \multicolumn{5}{|l|}{ Asthma } \\
\hline Asthma Control Questionnaire* & $1.7(0.3-2.6)$ & $1.1(0.4-2.9)$ & $0.3(0-2.9)$ & $<0.001$ \\
\hline Asthma Quality of Life Questionnaire† & $5.4(3.5-6.7)$ & $5.6(3.7-6.8)$ & $6.5(3.7-7.0)$ & 0.007 \\
\hline \multicolumn{5}{|l|}{ Lung function } \\
\hline \multicolumn{5}{|l|}{ Spirometry } \\
\hline $\mathrm{FEV}_{1}$, pre (\% predicted) & $88(45-106)$ & $86(66-119)$ & $97(73-125)$ & 0.009 \\
\hline $\mathrm{FEV}_{1}$, post $(\%$ predicted $)$ & $95(49-106)$ & $93(75-118)$ & $101(75-129)$ & 0.079 \\
\hline FVC, pre (\% predicted) & $102(64-118)$ & $97(75-126)$ & $106(77-144)$ & 0.575 \\
\hline FVC, post (\% predicted) & $107(62-120)$ & $99(74-126)$ & $107(78-141)$ & 0.754 \\
\hline $\mathrm{FEV}_{1} / \mathrm{FVC}$, pre (\%) & $79(61-90)$ & $76(63-92)$ & $81(66-93)$ & 0.096 \\
\hline $\mathrm{FEV}_{1} / \mathrm{FVC}$, post (\%) & $82(69-91)$ & $79(67-94)$ & $84(68-94)$ & 0.215 \\
\hline RV, post (\% predicted) $\ddagger$ & $79.5(74-92)$ & $74(39-126)$ & $74(47-118)$ & 0.567 \\
\hline TLC, post $(\%$ predicted $) \ddagger$ & $92.5(77-109)$ & $98(83-106)$ & $95(75-114)$ & 0.826 \\
\hline FRC, post (\% predicted)‡ & $68(54-90)$ & $62(40-95)$ & $64(41-88)$ & 0.554 \\
\hline RV/TLC, post (\%)‡ & $26.5(20-36)$ & $22(10-41)$ & $24(12-41)$ & 0.146 \\
\hline Reversibility FEV 1 & $7(-12-22)$ & $9(-6-20)$ & $4(-7-11)$ & 0.012 \\
\hline $\mathrm{Fe}_{\mathrm{NO}}(\mathrm{ppb})$ & $17(7-96)$ & $16(5-45)$ & $16(7-53)$ & 0.870 \\
\hline Diffusion capacity, kCO (\% predicted) & $98(70-116)$ & $97(69-133)$ & $95(69-134)$ & 0.890 \\
\hline $\mathrm{PD}_{20}(\mathrm{mg})$ & $0.31(0.04-1.8)$ & $0.37(0.04-1.8)$ & $1.8(1.8-1.8)$ & \\
\hline \multicolumn{5}{|l|}{ IOS } \\
\hline $\mathrm{R}_{5}(\mathrm{kPa} / \mathrm{s})$ & $0.58(0.24-1.11)$ & $0.69(0.41-1.39)$ & $0.57(0.17-0.97)$ & 0.022 \\
\hline $\mathrm{R}_{20}(\mathrm{kPa} / \mathrm{s})$ & $0.44(0.20-0.65)$ & $0.45(0.27-1.03)$ & $0.43(0.18-0.68)$ & 0.841 \\
\hline $\mathrm{R}_{5}-\mathrm{R}_{20}(\mathrm{kPa} / \mathrm{s})$ & $0.18(0.04-0.62)$ & $0.25(0.06-0.66)$ & $0.17(-0.1-0.48)$ & 0.001 \\
\hline $\mathrm{X}_{5}(\mathrm{kPa} / \mathrm{s})$ & $-0.16(-0.67$ to -0.1$)$ & $-0.26(0.87$ to -0.12$)$ & $-0.21(-0.43$ to -0.10$)$ & 0.138 \\
\hline $\mathrm{F}_{\text {res }}(\mathrm{Hz})$ & $17.3(9.2-30.4)$ & $22.6(10.7-28.9)$ & $18.5(8.4-28.7)$ & 0.001 \\
\hline
\end{tabular}

Data are presented as median (min-max).

* Scores of the Asthma Control Questionnaire range from 0 to 6, with lower scores indicating better asthma control.

†Scores of the Asthma Quality of Life Questionnaire range from 1 to 7, with higher scores indicating better asthma-specific quality of life.

$\ddagger$ Because of weight limitations for the body box $(<150 \mathrm{~kg})$, full spirometry could not be performed in all subjects; numbers for these parameters: $N B S+A=4, B S+A=15, B S-A=30$.

$\mathrm{BS}+\mathrm{A}$, bariatric surgery and asthma group; BS-A, bariatric surgery without asthma group; $\mathrm{Fe}_{\mathrm{NO}}$, exhaled nitric oxide; FRC, functional residual capacity; IOS, impulse oscillometry; NBS

$+\mathrm{A}$, no bariatric surgery and asthma group; $\mathrm{PD}_{20}$, provocative dose of methacholine inducing a $20 \%$ fall in $F E V_{1}$; RV, residual volume; TLC, total lung capacity.

\section{Weight loss}

Sixty-three percent of the BS+A and $69 \%$ of the BS-A group underwent gastric sleeve resection; the remaining subjects underwent gastric bypass surgery. BMI and abdominal circumference decreased in both bariatric surgery groups, and remained stable in the non-intervention group (figure $1 \mathrm{~A}, \mathrm{~B})$. Although the $\% \mathrm{EWL}$ was significantly lower in the $\mathrm{BS}+\mathrm{A}$ group compared with the $\mathrm{BS}-\mathrm{A}$ group (median $73 \%$ vs $84 \%$ respectively, $\mathrm{p}=0.045$ ), the BMI did not differ between the BS+A and BS-A group at baseline or at 12-month follow-up.

\section{Effect of weight loss on lung function tests}

Figure 2 and table 2 show the results of the follow-up of lung function. Twelve months after bariatric surgery $\mathrm{FEV}_{1} / \mathrm{FVC}$ and residual volume (RV) improved only in the BS-A group, whereas $\mathrm{FEV}_{1}$ (post), functional residual capacity (FRC) and total lung capacity (TLC) improved in BS-A and BS+A groups. These results can be better explained by a reduction in lung restriction than by a reduction in lung obstruction. RV/TLC, representing hyperinflation, did not change in any of the groups. $\mathrm{FEV}_{1} / \mathrm{FVC}, \mathrm{RV}, \mathrm{FEV}_{1}, \mathrm{FRC}$ and TLC did not change in the NBS + A group, confirming that the improvement in restrict- 


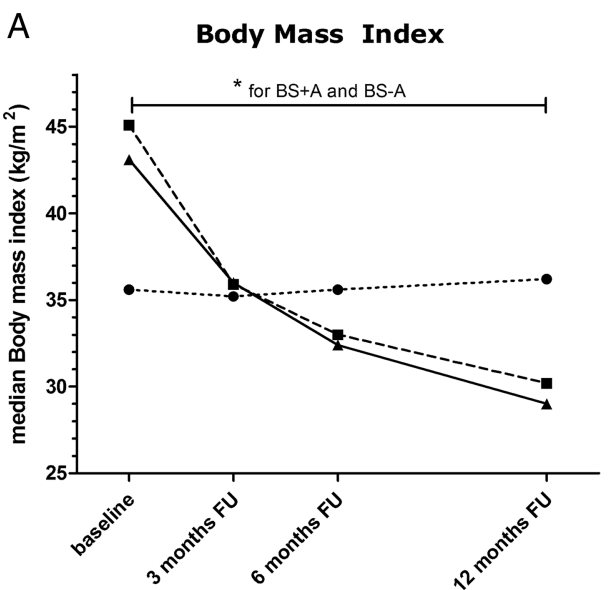

C Asthma Control Questionnaire

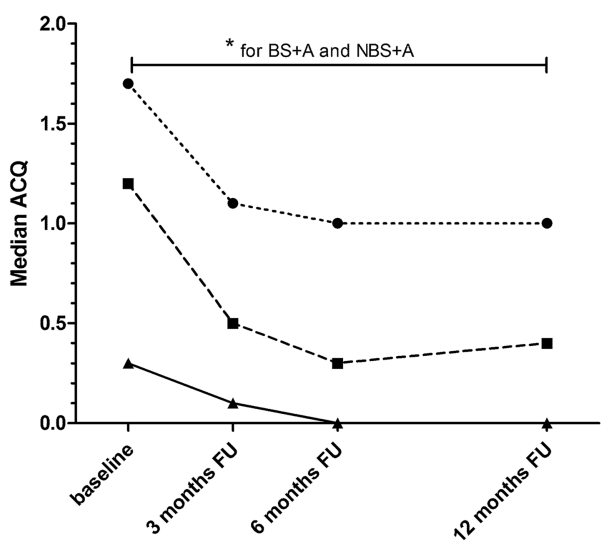

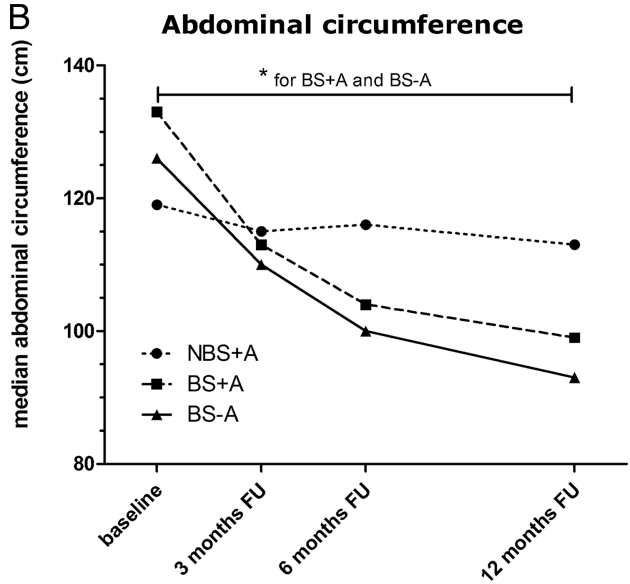

D Asthma Quality of Life Questionnaire

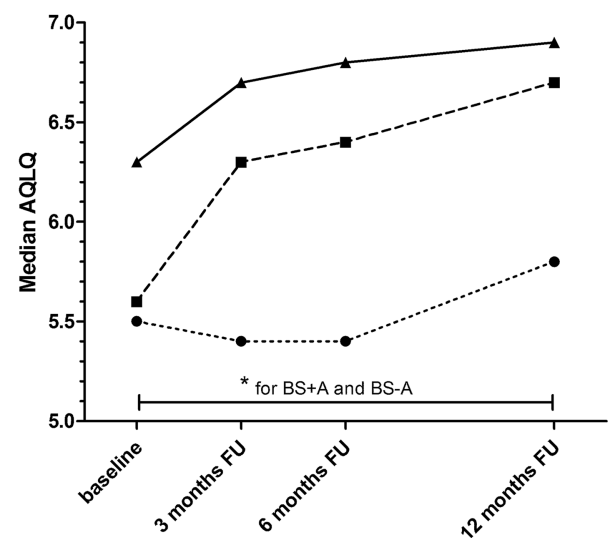

Figure 1 Effect of weight loss on asthma control. NBS+A, no bariatric surgery and asthma group (circles); BS+A, bariatric surgery and asthma group (squares); BS-A, bariatric surgery without asthma group (triangles). Only $p$ values for comparison between baseline and 12 -month follow-up were calculated; only significant $p$ values are shown $\left(^{*}\right)$. Scores of the Asthma Control Questionnaire (ACQ) range from 0 to 6 , with lower scores indicating better asthma control. Scores of the Asthma Quality of Life Questionnaire (AQLQ) range from 1 to 7, with higher scores indicating better asthma-specific quality of life. FU, follow-up.

ive lung function was due to weight loss. There was no significant change in diffusion capacity or exhaled nitric oxide $\left(\mathrm{Fe}_{\mathrm{NO}}\right)$ in any of the groups.

Impulse oscillometry, and especially $\mathrm{R}_{5}-\mathrm{R}_{20}$ as a measure of small airway function, showed a significant improvement in both bariatric groups (figure 2C). At baseline the $\mathrm{BS}+\mathrm{A}$ group had a significantly higher $\mathrm{R}_{5}-\mathrm{R}_{20}$ compared with the $\mathrm{BS}-\mathrm{A}$ group $(\mathrm{p}<0.001)$. At 12 -month follow-up the $\mathrm{R}_{5}-\mathrm{R}_{20}$ of the $B S$ + A group was comparable to the BS-A group. We found a correlation between $B M I$ and $\mathrm{R}_{5}-\mathrm{R}_{20}(\mathrm{R}=0.518, \mathrm{p}<0.001)$, and abdominal circumference and $\mathrm{R}_{5}-\mathrm{R}_{20} \quad(\mathrm{R}=0.415, \mathrm{p}<0.001)$. Also between ACQ and $\mathrm{R}_{5}-\mathrm{R}_{20}(\mathrm{R}=0.498, \mathrm{p}<0.001)$ and ACQ and $\mathrm{BMI}(\mathrm{R}=0.374, \mathrm{p}<0.001)$ (figure 3$)$.

In the $\mathrm{BS}+\mathrm{A}$ group, 24 subjects had a positive provocation test at baseline $\left(\mathrm{PD}_{20}<1.8 \mathrm{mg}\right)$. At 3, 6 and 12-month follow-up of these 24 subjects, 11 (of 24), 9 (of 20) and 13 (of 25) subjects had a negative provocation test, respectively. Median values increased significantly (figure $2 \mathrm{D}$ and table 2 ). In the $\mathrm{NBS}+\mathrm{A}$ group the $\mathrm{PD}_{20}$ did not increase significantly. No correlation was found between $\mathrm{PD}_{20}$ and $\mathrm{BMI}$, however we did found a significant correlation between $\mathrm{PD}_{20}$ and $\mathrm{R}_{5}-\mathrm{R}_{20}(\mathrm{R}=-0.337, \mathrm{p}<0.001)$.

\section{Effect of weight loss on asthma control}

The ACQ improved statistically and was clinically significant $(\Delta>0.5)$ in both asthma groups $(\mathrm{NBS}+\mathrm{A}$ and $\mathrm{BS}+\mathrm{A})$ at 12-month follow-up (figure 1C). The improvement in ACQ in the BS-A group was also statistically significant, but not clinically significant.

The AQLQ did not improve in the NBS + A group, but it did improve in the BS $+\mathrm{A}$ group (statistically and clinically significant $(\Delta>0.5))$ at 12-month follow-up, and also in the BS-A group (figure $1 \mathrm{D})$.

\section{Medication use}

In the BS+A group 10 subjects used inhaled corticosteroids (ICS) at inclusion in the study, of which 8 subjects agreed to stop for at least 6 weeks before provocation testing. Because of symptoms, one subject restarted ICS, and three subjects who did not use ICS before inclusion in the study were prescribed ICS because of progression of symptoms. So, a total of six subjects used ICS at baseline, with a median budesonide equivalence dose of $600 \mu \mathrm{g} /$ day. At 12-month follow-up, ICS was prescribed to six subjects, however only four subjects used the ICS, with a median budesonide equivalence of $600 \mu \mathrm{g} / \mathrm{day}$.

In the NBS + A group all 12 subjects used ICS at baseline, and in follow-up all subjects remained on ICS: the median budesonide equivalence dose remained stable (baseline $800 \mu \mathrm{g}$, 3 months $400 \mu \mathrm{g}$ and 12 months $800 \mu \mathrm{g})$. 
A

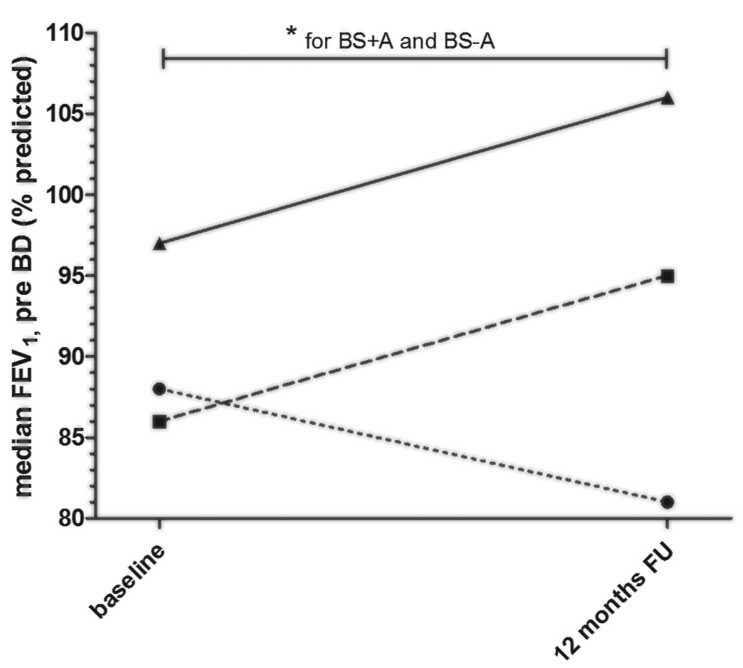

C

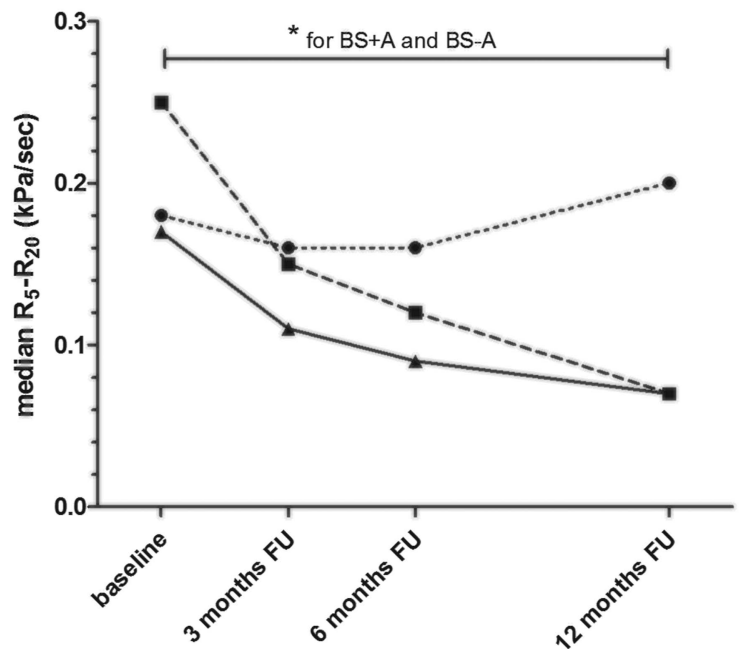

B $\quad$ FEV $_{1} /$ FVC

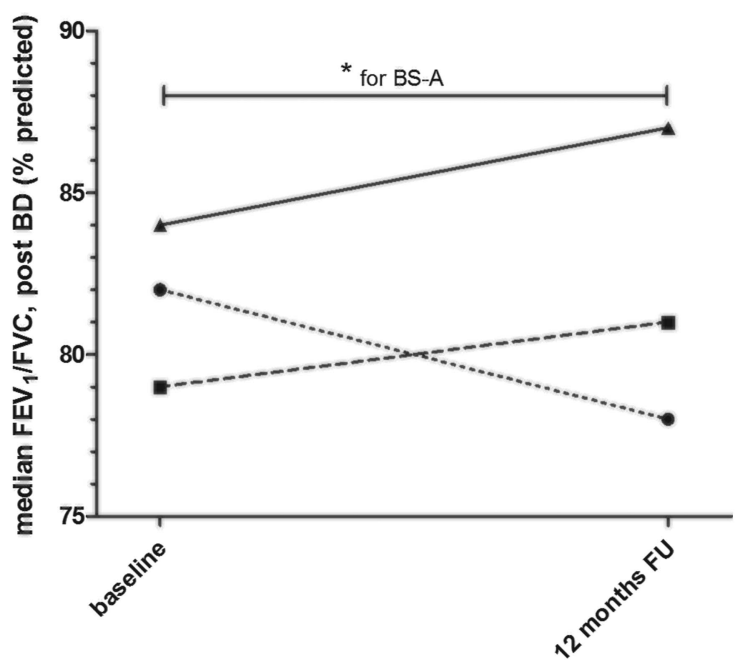

D $\quad \mathrm{PD}_{20}$ methacholine

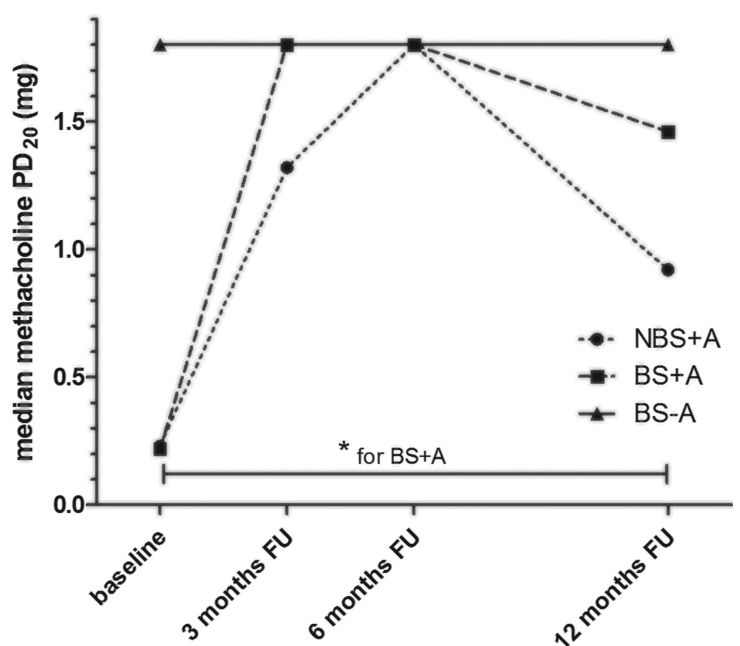

Figure 2 Effect of weight loss on lung function. NBS+A, no bariatric surgery and asthma group (circles); BS+A, bariatric surgery and asthma group (squares); BS-A, bariatric surgery without asthma group (triangles). Only p values for comparison between baseline and 12-month follow-up were calculated, only significant $\mathrm{p}$ values are shown $\left(^{*}\right)$. (A) $\mathrm{FEV} 1 \mathrm{BS}+\mathrm{A}$ median $86-95 \%$ predicted, $\mathrm{p}=0.001$; $\mathrm{BS}-\mathrm{A}$ median $97-106 \%$ predicted, $\mathrm{p}<0.001$; (B) FEV 1 /FVC BS-A 84-87\%, $\mathrm{p}<0.001$; (C) $\mathrm{R}_{5}-\mathrm{R}_{20} \mathrm{BS}+\mathrm{A} 0.25-0.07 \mathrm{kPa} / \mathrm{s}, \mathrm{p}<0.001$; $\mathrm{BS}-\mathrm{A}$ 0.17-0.07 kPa/s; $\mathrm{p}<0.001$. While there was at baseline a significant difference in $R_{5}-R_{20}$ between $B S+A$ and $B S-A$ group $(p<0.001)$, at 12-month follow-up there was no significant difference ( $p=0.919$ ); (D) $\mathrm{PD}_{20} \mathrm{BS}+\mathrm{A}$ median $0.22-1.46 \mathrm{mg}, \mathrm{p}=0.001$.

\section{Comorbidities and activity}

There were no significant changes in the Epworth Sleepiness Scale or Gastro-oesophageal Reflux Disease questionnaire in any group at any follow-up time point (3, 6 or 12 months) (data not shown). Daily activity as assessed by the number of steps a day did improve significantly in both bariatric surgery groups at 12-month follow-up (BS+A: median 4946 to 8312, $\mathrm{p}=0.030$; BS-A: median 5224 to $8094, \mathrm{p}=0.005$ ), and did not improve in the NBS+A group.

\section{Effect of weight loss on bronchial and systemic inflammation} Interleukin (IL)-6, IL-8, tumour necrosis factor (TNF)- $\alpha$ and granulocyte macrophage colony-stimulating factor (GM-CSF), markers of systemic inflammation, did not change at follow-up in any of the groups, although the levels of IL-6, TNF $\alpha$ and GM-CSF were at the lower limit of detection. Other markers of systemic inflammation, such as high-sensitivity C-reactive protein (hs-CRP), leptin and adiponectin, were significantly changed at 12-month follow-up in the BS+A and BS-A groups, and did not change in the NBS+A group (table 3).

At 12-month follow-up, bronchial biopsies were collected from 24 subjects $(8 \mathrm{BS}+\mathrm{A}, 14 \mathrm{BS}-\mathrm{A})$. Submucosal cell counts of eosinophils (EG2), neutrophils (NE), B cells (CD20), macrophages (CD68), CD4 $+\mathrm{T}$ cells or $\mathrm{CD} 8+\mathrm{T}$ cells did not change at 12-month follow-up in either the BS+A or BS-A group (figure 4, and online supplementary table S4). In contrast, mast cells (AA1) decreased significantly at 12-month follow-up in the BS+A group (median 118-61 cells $/ \mathrm{mm}^{2}, \mathrm{p}=0.036$ ), whereas $\mathrm{CD} 3+\mathrm{T}$ cells decreased significantly at 12-month follow-up only in the BS-A group (median 884-558 cells $/ \mathrm{mm}^{2}, \mathrm{p}=0.015$ ).

\section{Subgroup analysis}

When we divided the BS+A group into subjects who at baseline had a positive provocation test, and at 12-month follow-up 
Table 2 Effect of bariatric surgery on lung function

\begin{tabular}{|c|c|c|c|c|c|c|c|c|c|}
\hline & \multicolumn{3}{|l|}{$\mathrm{NBS}+\mathrm{A}$} & \multicolumn{3}{|l|}{$\mathrm{BS}+\mathrm{A}$} & \multicolumn{3}{|l|}{ BS-A } \\
\hline & Baseline & 12-month FU & p Value* & Baseline & 12-month FU & p Value* & Baseline & 12-month FU & p Value* \\
\hline \multicolumn{10}{|l|}{ Spirometry } \\
\hline $\mathrm{FEV}_{1}$, pre (\% predicted) & $88(45-106)$ & $81(71-117)$ & 0.553 & $86(66-119)$ & $95(67-119)$ & $<0.001$ & $97(73-125)$ & $106(75-134)$ & $<0.001$ \\
\hline $\mathrm{FEV}_{1}$, post ( $\%$ predicted) & 95 (49-106) & $88(70-118)$ & 0.759 & $93(75-118)$ & $100(79-117)$ & 0.001 & $101(75-129)$ & $108(80-139)$ & $<0.001$ \\
\hline FVC, pre (\% predicted) & $102(64-118)$ & $103(77-131)$ & 0.683 & $96(75-126)$ & $105(75-131)$ & 0.001 & $106(77-144)$ & $109(87-149)$ & 0.009 \\
\hline FVC, post (\% predicted) & $107(62-120)$ & $106(78-131)$ & 0.721 & $99(74-126)$ & $107(77-123)$ & 0.002 & $107(78-141)$ & 107 (84-149) & 0.046 \\
\hline $\mathrm{FEV}_{1} / \mathrm{FVC}$, pre $(\%)$ & $79(61-90)$ & $78(63-83)$ & 0.550 & $76(63-92)$ & 77 (57-92) & 0.246 & $81(66-93)$ & $83(73-99)$ & 0.021 \\
\hline $\mathrm{FEV}_{1} / \mathrm{FVC}$, post $(\%)$ & $82(69-91)$ & $78(66-86)$ & 0.239 & $79(67-94)$ & $81(69-94)$ & 0.327 & $84(68-94)$ & 87 (77-98) & $<0.001$ \\
\hline $\mathrm{RV}$, post (\% predicted) $\dagger$ & $79(74-92)$ & $65(55-105)$ & 0.285 & $80(39-126)$ & $79(76-115)$ & 0.789 & $72(47-96)$ & $82(43-137)$ & 0.013 \\
\hline TLC, post ( $\%$ predicted $) \dagger$ & $83(77-102)$ & $87(74-105)$ & 0.414 & $6(83-106)$ & $104(79-115)$ & 0.018 & $96(75-114)$ & $101(81-122)$ & $<0.001$ \\
\hline FRC, post (\% predicted) $\dagger$ & $65(54-90)$ & $69(61-85)$ & 0.593 & $62(40-95)$ & $88(53-117)$ & 0.008 & $64(41-77)$ & $94(59-145)$ & $<0.001$ \\
\hline RV/TLC, post (\%)† & $28(25-36)$ & $22(20-40)$ & 0.285 & $20(10-41)$ & $22(15-29)$ & 0.767 & $25(15-33)$ & $28(11-40)$ & 0.054 \\
\hline $\mathrm{Fe}_{\mathrm{NO}}(\mathrm{ppb}) \mp$ & $16(7-96)$ & $14(8-58)$ & 0.097 & $18(8-45)$ & $15(8-32)$ & 0.477 & $15(7-53)$ & $14(5-67)$ & 0.687 \\
\hline $\begin{array}{l}\text { Diffusion capacity, kCO } \\
\text { (\% predicted) }\end{array}$ & $98(70-116)$ & $95(71-136)$ & 0.202 & $97(69-133)$ & $99(67-118)$ & 0.483 & $95(77-134)$ & $91(69-127)$ & 0.179 \\
\hline $\mathrm{PD}_{20}$ methacholine $(\mathrm{mg})$ & $0.23(0.09-1.31)$ & $0.92(0.19-1.8)$ & 0.273 & $0.22(0.04-1.40)$ & $1.46(0.04-1.8)$ & 0.001 & & & \\
\hline \multicolumn{10}{|c|}{ 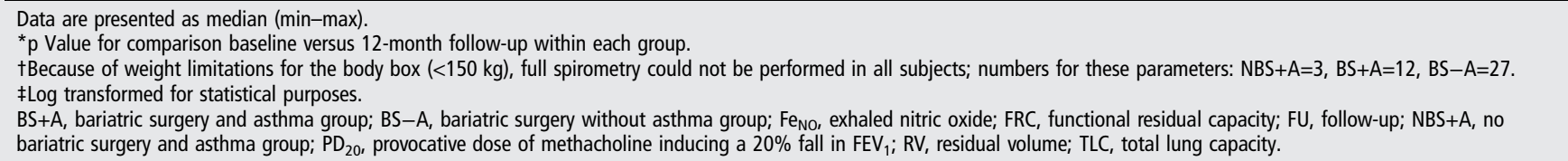 } \\
\hline
\end{tabular}

either a positive (non-responder) or negative (responder) provocation test, we found no differences between the two groups. In a subgroup analysis of patients with low immunoglobulin $\mathrm{E}$ (IgE) (' $\mathrm{T}_{\mathrm{H}}$ 2-low', $\operatorname{IgE}<100, \mathrm{n}=6$ ) versus high $\operatorname{IgE}\left({ }^{\prime} \mathrm{T}_{\mathrm{H}} 2\right.$-high', $\mathrm{n}=12$ ), we found that the $\mathrm{PD}_{20}$ only improved in the IgE-high group at 12-month follow-up (median 0.19-1.59 mg, $\mathrm{p}=0.003$ ), and not in the IgE-low group (median 0.53$0.99 \mathrm{mg}$ ). We found no differences in change in $\mathrm{R}_{5}-\mathrm{R}_{20}$.

\section{DISCUSSION}

In the present study bariatric surgery of morbidly obese patients with asthma was found to result in a significant improvement in small airway function $\left(\mathrm{R}_{5}-\mathrm{R}_{20}\right)$ and airway hyperresponsiveness ( $\mathrm{PD}_{20}$ methacholine), as well as asthma control and markers of bronchial (mast cell counts) and systemic inflammation. In contrast, there was no change in $\mathrm{FEV}_{1} / \mathrm{FVC}$.

There was no significant improvement in our primary endpoint $\mathrm{FEV}_{1} / \mathrm{FVC}$, a marker of airway obstruction, in the $\mathrm{BS}+\mathrm{A}$ group. However, in the $\mathrm{BS}-\mathrm{A}$ group, there was a statistically significant increased $\mathrm{FEV}_{1} / \mathrm{FVC}$, showing that weight loss affects airway diameter to some extent in patients without asthma. As the power of this study should be adequate, we might conclude that weight loss does not influence obstruction of the larger airways in asthma subjects. In line with previous reports, ${ }^{13} 15$ we found that weight loss induces an increase not only in TLC, but also FRC in both bariatric surgery groups, suggesting that the weight loss improves the relative restrictive lung function. Remarkably, the RV in the BS+A group did not change after bariatric surgery, whereas it did in the BS-A group. This could be because the RV at baseline was already relatively high in the BS + A group, so further improvement was unlikely. Perhaps the $\mathrm{BS}+\mathrm{A}$ group had peripheral airway obstruction before bariatric surgery due to different fat distribution compared with the BS -A group, since the abdominal circumference is higher in the $\mathrm{BS}+\mathrm{A}$ group. However, the RV/TLC ratio was the same in both bariatric groups, making a difference in obstruction less likely.

The main improvement in lung function was in $\mathrm{R}_{5}-\mathrm{R}_{20}$, a marker of small airway function. Whereas at baseline the $\mathrm{R}_{5}-$
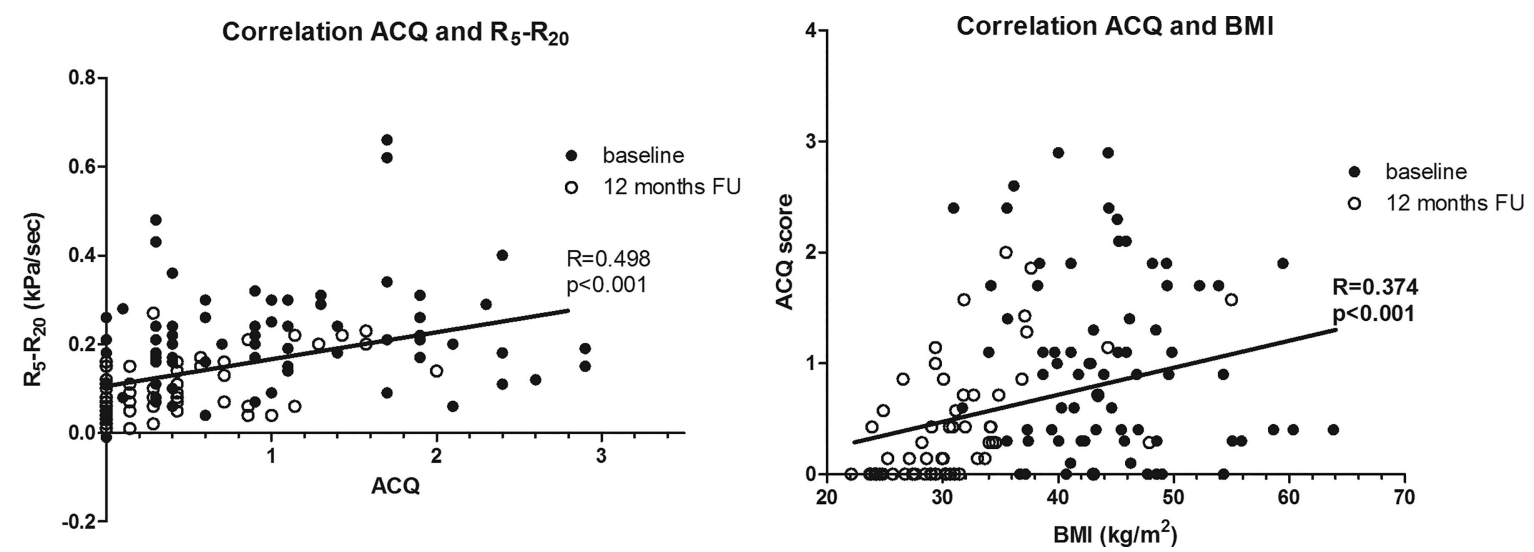

Figure 3 Correlation analysis of asthma control, small airway function and body mass index (BMI). Baseline data and 12-month follow-up data were used to calculate correlations. ACQ, Asthma Control Questionnaire. 


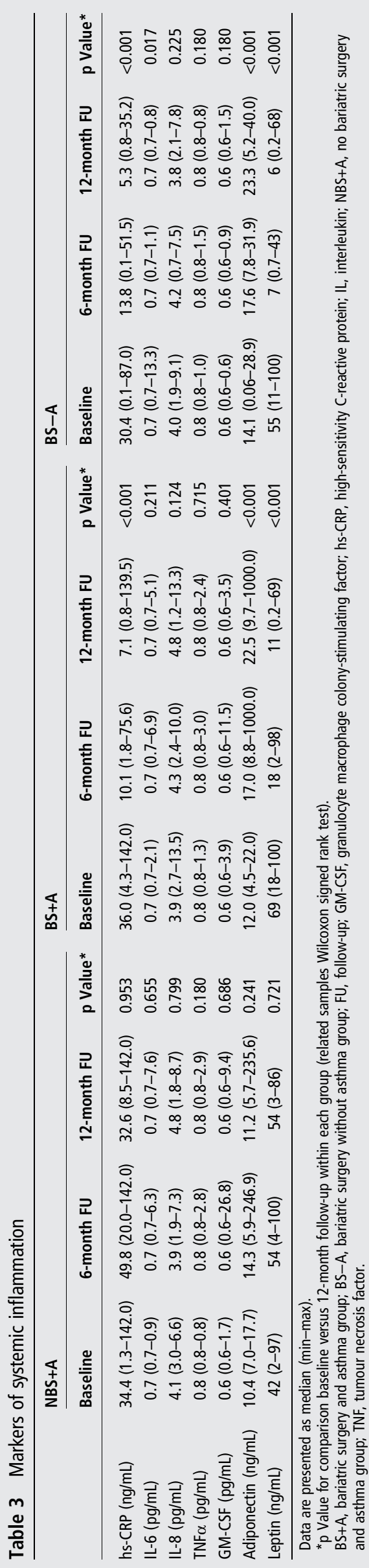

$\mathrm{R}_{20}$ in the $\mathrm{BS}+\mathrm{A}$ group was significantly worse compared with the BS-A group, 12 months after bariatric surgery, there was no longer a significant difference between the two groups. This remained when only non-smokers were analysed (data not shown). Our data are in line with Al-Alwan et al, ${ }^{16}$ who recently demonstrated that obese subjects with asthma have more collapsible peripheral airways than obese subjects without asthma, suggesting that altered lung mechanics play a role in the relationship between obesity and asthma. In addition to a correlation between $\mathrm{R}_{5}-\mathrm{R}_{20}$ and $\mathrm{BMI}$, we also found a correlation between $R_{5}-R_{20}$ and $A C Q$, suggesting that increased $R_{5}-R_{20}$ might explain the high symptom expression in obese subjects with asthma. Dixon et $a l^{13}$ have shown previously that bariatric surgery was more beneficial to subjects with normal IgE levels ( $\mathrm{T}_{\mathrm{H}}$ 2-low) in contrast to $\mathrm{T}_{\mathrm{H}}$ 2-high subjects, especially for small airway function. ${ }^{18}$ In contrast, the present study could not find a relation between $\mathrm{IgE}$ levels and small airway function, and only found a relation in the high IgE group and bronchial hyperresponsiveness. Besides a difference in BMI between Dixon and our study (51 and $45 \mathrm{~kg} / \mathrm{m}^{2}$ ), the IgE level of our ' $\mathrm{T}_{\mathrm{H}}$ 2-high' group was higher, and the ratio of number of subjects in the low versus high group was different in our study compared with Dixon.

Whereas other studies have shown only a reduction in bronchial hyperreactivity 12 months after bariatric surgery, ${ }^{13}{ }^{15}$ in some of our patients the $\mathrm{PD}_{20}$ methacholine became negative, despite the decreased use of ICS in the 12-month follow-up. This was in contrast to the NBS+A subjects, in whom we did not succeed to taper off the ICS. Whether they truly needed ICS is questionable. We found a negative correlation between $\mathrm{R}_{5}-\mathrm{R}_{20}$ and $\mathrm{PD}_{20}$, suggesting that the increased peripheral airway resistance is associated with more severe bronchial hyperreactivity.

One hypothesis explaining the relationship between obesity and asthma is the concept of spill over of systemic inflammation caused by obesity, to the lungs, resulting in bronchial inflammation. Although others have demonstrated that obese subjects with asthma have more neutrophilic inflammation compared with lean subjects with asthma, ${ }^{32} 33$ we have previously shown that there is no difference in neutrophil (or eosinophil) cell counts in bronchial biopsies between morbidly obese subjects with asthma and morbidly obese controls. ${ }^{11}$ As we found no differences in cell counts at baseline, we expected no change in any cell count after bariatric surgery. However, our results demonstrate that in subjects with asthma, mast cell counts in bronchial biopsies taken 12 months after bariatric surgery decreased significantly compared with baseline. This decrease in mast cells might reflect a better asthma control. This decrease in mast cells could in part explain the improved asthma control, because mast cells contribute to inflammation and tissue remodelling in asthma. As the study was powered to detect changes in the primary endpoint $\mathrm{FEV}_{1} / \mathrm{FVC}$ it could be that the number of patients investigated was not enough to detect subtle changes in bronchial inflammatory cells. Still none of the comparisons in cell counts showed a trend of being statistically different. Moreover, we found no differences in demographics between the group with follow-up bronchoscopy and those without (data not shown).

In line with previous reports, ${ }^{34}$ we found that systemic inflammation (hs-CRP, leptin and adiponectin in serum) decreased after bariatric surgery. These data suggest that a reduction in systemic inflammation may result in reduction in local airway inflammation in subjects with asthma. However, the improvement after weight loss of especially the small airway 


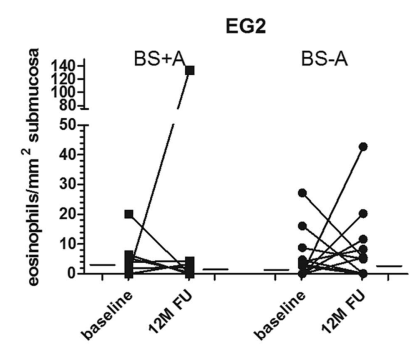

CD20

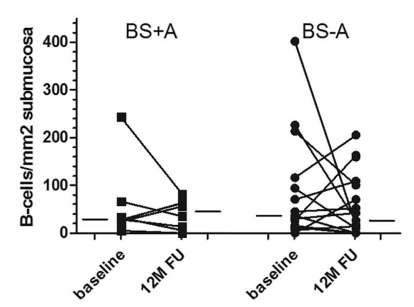

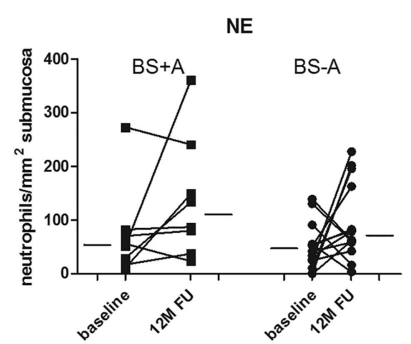

CD8

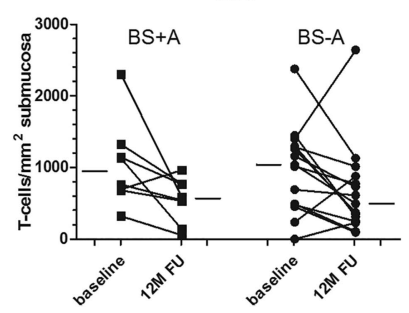

AA1

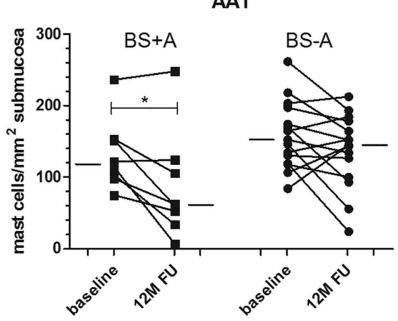

CD4

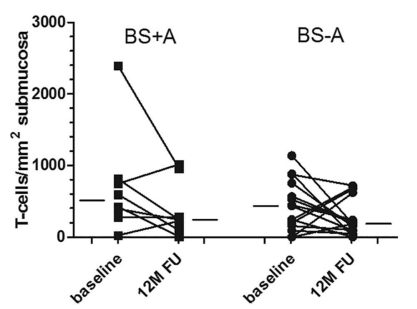

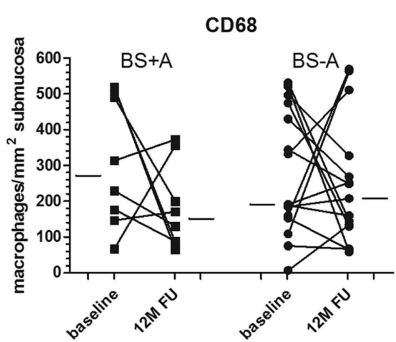

CD3

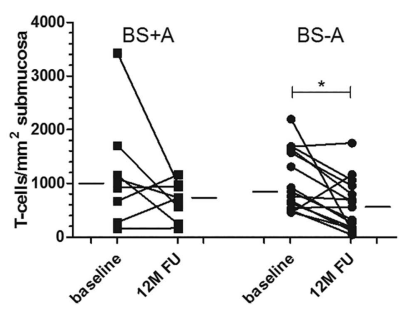

Figure 4 Submucosal cell counts of bronchial biopsies, before and 12 months after bariatric surgery. Bronchial submucosal cell count in morbidly obese subjects before and 12 months after bariatric surgery, with ( $B S+A, n=8$, squares) and without asthma ( $B S-A$, n=14, circles). $p$ Values were calculated for the comparison between baseline and 12-month follow-up (12M FU) within each group, only significant $p$ values are shown (*). Horizontal line represents median.

function, and the correlation between small airway function and ACQ reflects that bariatric surgery also improves the mechanical properties of the lungs. The observation that some obese patients develop asthma and other obese subjects do not has led to several hypotheses. Our data are in line with the suggestion made by Al-Alwan et al, ${ }^{16}$ that obese subjects with asthma may be predisposed to the effect of obesity on small airways, which is supported by their data obtained by computational remodelling of airway wall stiffness and thickness, predicting a relationship between airway hyperresponsiveness and BMI. ${ }^{35}$

The strengths of our study are that we included an obese control group of subjects without asthma, as well as a control group of obese subjects with asthma without bariatric surgery. In addition, the group size in our study was larger than previous studies, and we not only performed data collection at 12 months but also at 3 and 6 months of follow-up. Furthermore, the diagnosis of asthma was performed strictly according to the GINA guidelines, as a doctor diagnosis of asthma in which symptoms play a major role has previously been shown to be not suitable for diagnosing asthma in patients with obesity. ${ }^{19} 36$ Finally, participation was good and only few dropped out during the 12-month follow-up.

There are also some limitations to our study. First of all, we did not include a lean asthma group. Second, our obese asthma group without bariatric surgery is not fully comparable to both bariatric surgery groups due to differences in recruitment strategy. As a result, for example, the BMI is lower and this is because the frequency of patients with morbid obesity and asthma is low in our outpatient clinic. As a second bronchoscopy was optional, a bias is possible. Finally, bronchial biopsies were taken centrally, and therefore are not optimally suited to establish a possible relationship with peripheral airway function.

In summary, this is the first study that examined a wide variety of clinical, physiological, systemic and bronchial mucosal inflammatory parameters before and after bariatric surgery in morbidly obese subjects with asthma and morbidly obese control subjects. Although we found no improvement in our primary endpoint $\mathrm{FEV}_{1} / \mathrm{FVC}$, we did find improvement in asthma control, quality of life, medication use and $\mathrm{PD}_{20}$ methacholine. The significant improvement of $\mathrm{R}_{5}-\mathrm{R}_{20}$ (peripheral airway function) after bariatric surgery, which was associated with $\mathrm{BMI}, \mathrm{ACQ}$ and $\mathrm{PD}_{20}$, suggests that peripheral airways play a major role in the relationship between obesity and asthma. Finally, bariatric surgery also decreased markers of systemic inflammation, and mast cell counts in central bronchial submucosa of obese subjects with asthma. Collectively these findings emphasise that weight loss as achieved by bariatric surgery should be a cornerstone in the treatment of morbidly obese patients with asthma. Further research regarding the role of small airways in obese asthma is needed.

Correction notice This article have been corrected since it was published Online First. The 'Provenance and peer review' has been corrected.

Acknowledgements We wish to thank Mr Erwin Birnie for statistical advice, and Miss Vera van Rijn and Mrs Annemarie van Schadewijk for their help with the analysis of the bronchial biopsies and systemic inflammation. We are grateful for the help of all pulmonologists, the staff in the Respiratory Laboratory, Department of Clinical Chemistry, and surgeons, anaesthetists and other members of the Bariatric Surgery Team at the Sint Franciscus Gasthuis.

\section{Collaborators Annemarie van Schadewijk.}

Contributors Conception and design: AvH, AR, MCC, CT, PH, G-JB. Analysis and interpretation: AvH, G-JvdG, CT, PH, G-JB, AvS. Drafting of the manuscript for important intellectual content: AvH, AR, MCC, LB, G-JvdG, CT, PH, G-JB. Guarantor: AvH, CT, PH, G-JB.

Funding This research was supported by grants from Foundation Research and Development Department of Internal Medicine Sint Franciscus Gasthuis (Stichting Onderzoek en Ontwikkeling Interne Specialismen Sint Franciscus Gasthuis).

Competing interests None.

Patient consent Obtained.

Ethics approval Toetsingscommissie Wetenschappenlijk Onderzoek Rotterdam e.o.

Provenance and peer review Not commissioned; externally peer reviewed.

\section{REFERENCES}

1 Bateman ED, Hurd SS, Barnes PJ, et al. Global strategy for asthma management and prevention: GINA executive summary. Eur Respir J 2008;31:143-78.

2 Eder W, Ege MJ, von Mutius E. The asthma epidemic. N Engl J Med 2006;355:2226-35.

3 Chinn S. Asthma and obesity: where are we now? Thorax 2003;58:1008-10. 
4 Camargo CA Jr, Weiss ST, Zhang S, et al. Prospective study of body mass index, weight change, and risk of adult-onset asthma in women. Arch Intern Med 1999;159:2582-8.

5 Mosen DM, Schatz M, Magid DJ, et al. The relationship between obesity and asthma severity and control in adults. J Allergy Clin Immunol 2008;122:507-11.e6.

6 Sutherland ER, Goleva E, Strand M, et al. Body mass and glucocorticoid response in asthma. Am J Respir Crit Care Med 2008;178:682-7.

7 Moreira A, Bonini M, Garcia-Larsen V, et al. Weight loss interventions in asthma: EAACl evidence-based clinical practice guideline (part I). Allergy 2013;68:425-39.

8 Kushner RF. Clinical assessment and management of adult obesity. Circulation 2012;126:2870-7.

9 Haldar P, Pavord ID, Shaw DE, et al. Cluster analysis and clinical asthma phenotypes. Am J Respir Crit Care Med 2008;178:218-24.

10 Desai D, Newby C, Symon FA, et al. Elevated sputum interleukin-5 and submucosal eosinophilia in obese individuals with severe asthma. Am J Respir Crit Care Med 2013;188:657-63.

11 van Huisstede $A$, Rudolphus A, van Schadewijk A, et al. Bronchial and systemic inflammation in morbidly obese subjects with asthma: a biopsy study. Am J Respir Crit Care Med 2014;190:951-4.

12 Maniscalco M, Zedda A, Faraone S, et al. Weight loss and asthma control in severely obese asthmatic females. Respir Med 2008;102:102-8.

13 Dixon AE, Pratley RE, Forgione PM, et al. Effects of obesity and bariatric surgery on airway hyperresponsiveness, asthma control, and inflammation. J Allergy Clin Immunol 2011;128:508-15.e1-2.

14 Lombardi C, Gargioni S, Gardinazzi A, et al. Impact of bariatric surgery on pulmonary function and nitric oxide in asthmatic and non-asthmatic obese patients. J Asthma 2011;48:553-7.

15 Boulet LP, Turcotte $H$, Martin J, et al. Effect of bariatric surgery on airway response and lung function in obese subjects with asthma. Respir Med 2012;106:651-60.

16 Al-Alwan A, Bates JH, Chapman DG, et al. The nonallergic asthma of obesity. A matter of distal lung compliance. Am J Respir Crit Care Med 2014;189:1494-502.

17 Sideleva O, Suratt BT, Black KE, et al. Obesity and asthma: an inflammatory disease of adipose tissue not the airway. Am J Respir Crit Care Med 2012;186:598-605.

18 Chapman DG, Irvin CG, Kaminsky DA, et al. Influence of distinct asthma phenotypes on lung function following weight loss in the obese. Respirology 2014;19:1170-7.

19 van Huisstede A, Castro Cabezas M, van de Geijn GJ, et al. Underdiagnosis and overdiagnosis of asthma in the morbidly obese. Respir Med 2013;107:1356-64.

20 Miller MR, Hankinson J, Brusasco V, et al. Standardisation of spirometry. Eur Respir J 2005;26:319-38

21 Quanjer PH, Tammeling GJ, Cotes JE, et al. Lung volumes and forced ventilatory flows. Report Working Party Standardization of Lung Function Tests, European Community for Steel and Coal. Official Statement of the European Respiratory Society. Eur Respir J Supp/ 1993;16:5-40.
22 American Thoracic Society; European Respiratory Society. ATS/ERS recommendations for standardized procedures for the online and offline measurement of exhaled lower respiratory nitric oxide and nasal nitric oxide, 2005. Am J Respir Crit Care Med 2005;171:912-30.

23 Huang YC, O'Brien SR, Maclntyre NR. Intrabreath diffusing capacity of the lung in healthy individuals at rest and during exercise. Chest 2002;122:177-85.

24 Sterk PJ, Fabbri LM, Quanjer PH, et al. Airway responsiveness. Standardized challenge testing with pharmacological, physical and sensitizing stimuli in adults. Report Working Party Standardization of Lung Function Tests, European Community for Steel and Coal. Official Statement of the European Respiratory Society. Eur Respir J Supp/ 1993;16:53-83.

25 Crapo RO, Casaburi R, Coates AL, et al. Guidelines for methacholine and exercise challenge testing-1999. This official statement of the American Thoracic Society was adopted by the ATS Board of Directors, July 1999. Am J Respir Crit Care Med 2000;161:309-29.

26 Juniper EF, Guyatt GH, Cox FM, et al. Development and validation of the Mini Asthma Quality of Life Questionnaire. Eur Respir J 1999:14:32-8.

27 Juniper EF, O'Byrne PM, Guyatt GH, et al. Development and validation of a questionnaire to measure asthma control. Eur Respir J 1999;14:902-7.

28 Johns MW. A new method for measuring daytime sleepiness: the Epworth Sleepiness Scale. Sleep 1991;14:540-5.

29 Jones R, Junghard O, Dent J, et al. Development of the GerdQ, a tool for the diagnosis and management of gastro-oesophageal reflux disease in primary care. Aliment Pharmacol Ther 2009;30:1030-8.

30 Grundy SM, Brewer HB Jr, Cleeman Jl, et al. Definition of metabolic syndrome: Report of the National Heart, Lung, and Blood Institute/American Heart Association conference on scientific issues related to definition. Circulation 2004;109: 433-8.

31 British Thoracic Society Bronchoscopy Guidelines Committee, a Subcommittee of Standards of Care Committee of British Thoracic Society. British Thoracic Society guidelines on diagnostic flexible bronchoscopy. Thorax 2001;56(Suppl 1):i1-21.

32 Telenga ED, Tideman SW, Kerstjens HA, et al. Obesity in asthma: more neutrophilic inflammation as a possible explanation for a reduced treatment response. Allergy 2012;67:1060-8.

33 Todd DC, Armstrong S, D'Silva L, et al. Effect of obesity on airway inflammation: a cross-sectional analysis of body mass index and sputum cell counts. Clin Exp Allergy 2007;37:1049-54.

34 Kim SH, Sutherland ER, Gelfand EW. Is there a link between obesity and asthma? Allergy Asthma Immunol Res 2014;6:189-95.

35 Bates JH, Dixon AE. Potential role of the airway wall in the asthma of obesity. J Appl Physiol (1985) 2015;118:36-41.

36 Scott S, Currie J, Albert P, et al. Risk of mis-diagnosis, health related quality of life and body mass index in overweight patients with doctor diagnosed asthma. Chest 2012;141:616-24. 